\title{
"Additive Manufacturing applications in Defence Support Services: Current Practices and Framework for implementation"
}

\author{
Alessandro Busachi $^{\mathrm{a} *}$, John Erkoyuncu ${ }^{\mathrm{a}}$, Paul Colegrove ${ }^{\mathrm{a}}$, Richard Drake ${ }^{\mathrm{b}}$, Chris Watts $^{\mathrm{b}}$, Stephen Wilding $^{\mathrm{b}}$ \\ ${ }^{a}$ Manufacturing Department, Cranfield University, \\ befence Systems Technology, Babcock International, Bristol, United Kingdom
}

* Corresponding author. Tel.:+447790779432; E-mail address: a.busachi@cranfield.ac.uk

\section{Abstract}

This research investigates through a systems approach, "Additive Manufacturing" (AM) applications in "Defence Support Services" (DS2). AM technology is gaining increasing interest by DS2 providers, given its ability of rapid, delocalised and flexible manufacturing. From a literature review and interviews with industrial and academic experts, it is apparent that there is a lack of research on AM applications in DS2. This paper's contribution is represented by the following which has been validated extensively by industrial and academic experts: 1) DS2 current practices conceptual models, 2) a framework for AM implementation and 3) preliminary results of a next generation DS2 based on AM. To carry out the research, a Soft System Methodology was adopted. Results from the research increased the confidence of the disruptive potential of AM within the DS2 context. The main benefits outlined are 1) an increased support to the availability given a reduced response time, 2) reduced supply chain complexity given only supplies of raw materials such as powder and wire, 3) reduced platform inventory levels, providing more space and 4) reduced delivery time of the component as the AM can be located near to the point of use. Nevertheless, more research has to be carried out to quantify the benefits outlined. This requirement provides the basis for the future research work which consists in developing a software tool (based on the framework) for experimentation purpose which is able to dynamically simulate different scenarios and outline data on availability, cost and time of service delivered.

\section{Introduction}

Current technological developments in "Additive Manufacturing" (AM) have increased confidence in the disruptive potential of this technology. Leading organisations in Industrial Product-Service System's (IPS2) are increasingly investing in R\&D activities to better understand AM, its limitations and how to benefit now and in the future from its potential. AM capability acquisition may represent a source of competitive advantage and a means to develop new sources of income. In contrast, ignoring AM may lead to a loss of competitiveness or opportunities. This paper contributes to the current research effort on "AM applications in "Defence Support Services" (DS2) for Royal Navy's platforms. AM is an emerging and promising technology which is an enabler of rapid, delocalised and flexible manufacturing (Busachi et al., 2015). The main advantages of AM applications in DS2 are to provide platforms with the ability to sustain their systems, recover its capability after damage, solve obsolescence issues (Erkoyuncu et al., 2015) and collapse dramatically the supply chain (Busachi et al., 2015). Through a literature review and unstructured interviews with a leading Defence Support Service provider, it was possible to identify a lack of knowledge and research on AM applications in DS2. This lack of research leads to a wide knowledge gap, which has to be addressed to reduce the barriers of AM adoption by DS2 providers. A general lack of data regarding design and engineering aspects together with the absence of comparison with traditional DS2 leads to a high degree of uncertainty. This leads to key industrial decision makers being reluctant to acquire AM capability. This paper's contribution to knowledge is represented by a Framework which defines the process to assess AM applications in DS2 and identify feasible and optimal solutions. The framework provides a mechanism to shift the current research's "Technology Readiness Level" (TRL) from TRL-2 "Technology Concept" to TRL-3 "Proof of Concept"

\section{Literature Review}

Ivanova et al. (2013) defines "Additive Manufacturing" (AM) as a group of emerging and promising technologies that create an object by adding material bottom-up. AM enables rapid conversion of CAD files into physical products by merging layer upon layer of heated material (RAND, 2013). It is defined as the "process of joining materials to make objects from three-dimensional (3D) 
model data, usually layer by layer, as opposed to subtractive manufacturing methodology"(ASTM, 2013). Exploiting “Additive Manufacturing" (AM) opportunities for "Defence Support Services" (DS2) is a fairly new concept. Pérès and Noyes, (2006) introduced the concept of spare parts production with $\mathrm{AM}$, on request and in short time for isolated platforms in which space is a constraint such as orbital stations and generic military equipment. The conclusions of their study were the demonstration of the feasibility of the concept. The main limitations outlined were the immaturity of AM technology. Iwata and Mavris, (2013) developed a dynamic model to simulate DS2 for aerospace vehicles. With this research the importance of dynamic simulation for DS2 was outlined. Moreover they outlined that $60 \%$ to $70 \%$ of total cost of ownership of a defence platform relies on support services and maintenance.

Khajavi et al., (2014) combined DS2 with AM and dynamic simulation and evaluated the impact of $A M$ implementation of support services for F-18 Super Hornet Fighter jet. The research investigated a set of possible supply chain configurations with delocalised manufacturing. Major barriers outlined were the AM equipment cost and personnel intensiveness. A. Busachi et al., (2015b) investigated wire based AM technology for support availability of system on defensive platforms. In the same year Busachi et al., (2015a) investigated the available AM technologies and related approaches to measure the product cost. Apte and Rendon (2009) carried out a research on the optimisation of availability of systems on Navy platforms. According to their conclusions in order to improve the availability of a complex weapon system, it is crucial to ensure: 1) quality of spares which implies higher reliability and longer life of the component, 2) availability of spares on board in order to reduce delay times and 3) establish a wellstructured preventive maintenance cycle to reduce failure rates of the system, 4) perform " 5 Whys" or "Root Cause" Analysis on components that fail and assess criticality of failure with respect to mission success and finally 6) establish performance based contracts with external contractors to improve cost-reduction activities.

The current industrial applications of AM within the defence sector have been reviewed. MBDA is a leading European consortium in the missile industry. The consortium has introduced AM in its business since 1988. Initial application of AM was Rapid Prototyping to support the product development phase and reduce the time-to-market of new designs. In a second phase AM has been used for the production of complex tooling solutions. In recent years MBDA decided to exploit the potential opportunities arising from AM and expanded its Research and Development activities. In 2011 they established a collaboration with Cranfield University's Laser Processing and Welding Engineering Centre. The focus of the collaboration was "Wire + Arc Additive Manufacturing" (WAAM) process methodology to print Missile structures made of Titanium (Ti6Al4V) (MBDA, 2015). Another important player in the application of AM in Missile sector is the "Aviation and Missile Research Development and Engineering Centre" (AMRDEC) of the US Army (US Army, 2015). The centre has a collaboration with NASA and the University of Alabama. In May 2014, the Centre, established a Research and Development team called Integrated Product Team (IPT) that works on the application of ALM for the manufacturing of missiles. The main research aim is to develop a stronger and lighter structure which can manage the strong vibrations that occur during flight. In 2010 the US Army established the "Rapid Equipping Force" (REF) to support the Army in Afghanistan (REF, 2015). The Mission of the REF is to provide immediate solutions to the urgent challenges faced by soldiers. This has been possible through the deployment of mobile laboratories called "Expeditionary Labs". These labs are based on an ALM system and a CNC machine and a multidisciplinary team made of scientists and engineers. Each lab has a cost of around \$2.8 million. REF has been considered a successful solution for the development of non-standard quick reaction equipping of US soldiers. This is due to its ability to provide the Army with customised solutions to changing missions and environment. The labs aim to produce low volume quantities, more specifically "limited quantities of specialised capabilities".

\section{Research Methodology}

The research methodology adopted is presented in Figure 1 - Research Methodology. The proposed methodology is based on an adaptation of "Soft System Methodology" (SSM) (Checkland, 2001). Soft System Methodology is particularly suitable for enterprise modelling and is used in problem solving processes in order to structure the analysis and the solution development. The aim of the methodology is to develop visual models using system rules. The proposed methodology used to carry out this research is based on SSM and has been tailored to better fit the research aim. An initial literature review has been carried out before performing primary research. A mix of qualitative methods such as interviews, observation and deduction has been utilised to carry out the investigation of current practices. In order to reduce subjectivity, experts in 
"Defence Support Services" (DS2) have been identified and involved in the research for collecting information and validation of the result.

\begin{tabular}{|l|c|c|}
\hline \multicolumn{1}{|c|}{ Position } & Experience & Interviews \\
\hline Engineering Director & 10 years & $6 \mathrm{hrs}$ \\
\hline $\begin{array}{l}\text { Technology Acquisition } \\
\text { Lead }\end{array}$ & 6 years & $6 \mathrm{hrs}$ \\
\hline $\begin{array}{l}\text { In-Service Support } \\
\text { Manager }\end{array}$ & 5 years & $6 \mathrm{hrs}$ \\
\hline $\begin{array}{l}\text { Defence Equipment } \\
\text { and Support Officer (1) }\end{array}$ & 5 years & $3 \mathrm{hrs}$ \\
\hline $\begin{array}{l}\text { Defence Equipment } \\
\text { and Support Officer (2) }\end{array}$ & 5 years & $3 \mathrm{hrs}$ \\
\hline
\end{tabular}

Table 1 - Experts table

Phase 2, current practices has been developed through interviews and conceptual modelling. Results have been consequently validated. The sequential phase involved the conceptual framework development which has been carried out using current practices and results of a critical review published in a journal paper (Busachi et al, 2015). Finally the next generation DS2 have been outlined through deduction of phase 1 and phase 2 and all possible scenarios have been listed and validated with experts. Table 1 - Experts table shows the list of experts involved in the interviews and validations.

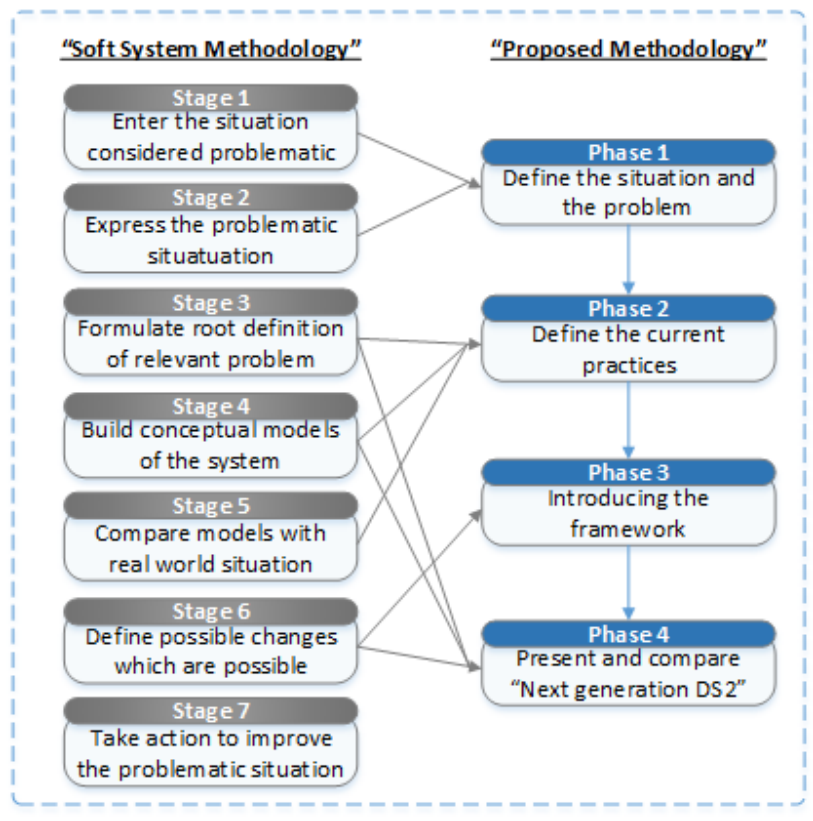

Figure 1 - Research Methodology

Phase 1 - "Define the situation and problem": AM is considered a promising technology. Especially for DS2 providers given their requirement to operate with disrupted and extended supply chain. AM is particularly suitable for delocalised manufacturing of low to medium volume productions, moreover the technology allows production of any type of geometry without affecting the productivity. The current problem faced, is the inability to assess AM applications in support services practices for the Royal Navy. DS2 are complex systems and current review of literature outlined that there is a lack of research on AM applications for DS2. Current practices have to be investigated and defined, furthermore a framework has to be developed to outline all the necessary phases required to assess the application of the technology, finally the next generation of DS2 based on AM have to be presented and compared with current practices.

Phase 2 - "Current practices": this phase is based on primary research and interviews with industrial experts of DS2. The aim of the phase is to develop conceptual models that outline DS2 as systems. The conceptual models need to provide an extensive knowledge on DS2 outlining its elements, the links, the possible scenarios, the operating environment in which they operate and finally a "Key Performance Indicator" (KPI) through which a DS2 can be measured. This will cover a knowledge gap on DS2 literature.

Phase 3 - "Framework": the framework represents the second contribution to knowledge. It provides an exhaustive and detailed approach on how to perform an assessment of AM applications in DS2. The framework is also considered as a reference for the development of the dynamic model. Phase 4 - "Present and compare Next generation DS2": the last phase of the methodology consists of developing, presenting and comparing a DS2 based on AM. Phase 4 results have been obtained by merging Phase 2 and 3 and logic deductions which have been validated by expert judgement in both industry and academia.

\section{Defining the situation and problem}

DS2 are complex "Industrial Product-Service Systems" (IPS2) which have the ability to deliver on a turn-key basis equipment, training, technical support, spare parts, platforms, supply chain management, project management, people, revamping, upgrades, expertise and know-how. DS2 are required to be highly responsive, operate in mission and safety critical environments anywhere in the world and support complex engineering systems featured with advanced technologies. DS2 can be described as systems made of wide range of elements featured with complexity, interconnectedness, 
uncertainties and variability. They have a dynamic and stochastic nature featured with randomness which implies complex dynamics. The states of the system have to be determined probabilistically and the behaviour has to be observed over time (i.e. 30 years). AM applications in Support Services may provide precious advantages in terms of time, cost and availability of systems giving both the service provider and the "Ministry of Defence» (MoD) cost and strategic advantages. AM based DS2 differentiate themselves from traditional DS2 mainly due to their ability for delocalised manufacturing of any kind of geometry. Manufacturing can occur within a port, a support ship or a defensive platform such as an aircraft carrier, a destroyer or a submarine. This is possible through an implementation of a "Rapid Availability Support System" (RAS2) a robust and autonomous manufacturing system based on AM, which merges together equipment, people, software and competencies. The mission of a RAS2 is to support engineering systems which are under "Contracting for Availability" (CfA), therefore the aim is to maximise "Availability" through the rapid manufacture of any type of spare part required by the engineering system in order to operate and deliver its capability. Moreover, having manufacturing capability on-board, allows the platform to recover its structure after shocks providing a strategic advantage and improve survivability metric.

\subsection{RAS2 Technology Maturity}

Current research effort on RAS2 has been initiated by the "Through-Life Engineering Services" (TES) Centre of Cranfield University on input of a leading British DS2 provider. The Centre is currently developing the technology to TRL-4 which will allow the transition to TRL-5 with the possibility to develop a physical prototype of the system. The RAS2 technology is identified as the collection of the scientific knowledge, algorithm, equations, techniques, processes and decision support system developed or identified in TRL-1, TRL-2 and TRL-3. The transition from TRL-2 to TRL-3 allows definition of the preliminary engineering of the physical system and definition of the process to implement it. The know-how relies on how to optimise the DS2 and make it financially sustainable and profitable. It has to be outlined that the RAS2 is not a product which will be sold, it is a system which delivers a service. The service which is delivered is the support to availability of the engineering systems on the platform which are under "Contracting for Availability" (CfA). Finally, in order to allow this shift from TRL-2 to TRL-3, a Framework for assessment and optimisation of AM in DS2 has been developed and presented in this paper. The Framework is the logic which will control the Dynamic Modelling through which the users can develop further scientific knowledge. Dynamic modelling is necessary to cope with the complexity of a comprehensive assessment of AM applications in DS2. The complexity is given by: an extensive involvement of different systems with various behaviours which needs to be observed and tested and the extensive presence of different options and solutions. Furthermore, given the need of comparisons between each solution, visualisation techniques are necessary to allow the user to get a comprehensive understanding of the different behaviours. Finally, dynamic simulation is required also because a physical system does not exist.

\subsection{Current Challenge}

The current challenge which is faced is the inability to answer exhaustively and with evidence a set of critical questions, both technical and financial. The "inability" is given by a lack of scientific knowledge and by the absence in the physical world of an AM based DS2. There is no data, information and knowledge on AM based DS2 leading management to develop only intuitions on its feasibility. This situation led to direct the research effort in the development of reliable means to form solid judgement/opinions based on understanding of the complexity of the behaviours of DS2 and on AM based DS2. Data and information needs to be generated to support the identification of feasible solutions. Moreover, it is necessary to simulate dynamically the feasible solutions to understand the behaviour under normal conditions and also carry out experimentation with different internal and external scenarios. The Framework presented in this paper represents the logic which controls the dynamic model, outlining all the controllable variables which have to be experimented. The framework has been developed following the MECE principle, "mutually exclusive, collectively exhaustive". It is considered comprehensive given a validation by expert judgement from a leading DS2 provider. In order to assess the applications of AM in DS2 a dynamic model needs to be developed to carry out experimentation. The Framework is embedded in the dynamic model and represents its control. The Framework is made of several logic flows/algorithms which are semiautomatic, as inputs from a user are required. The logic flows/algorithms are represented as visual models and need to be translated into executable codes in order to run the dynamic model. The dynamic model is used to develop the knowledge for AM in DS2. This process allows the authors to answer with confidence and scientifically critical questions related to AM in DS2 and assess its feasibility. 


\section{DS2 Current Practices}

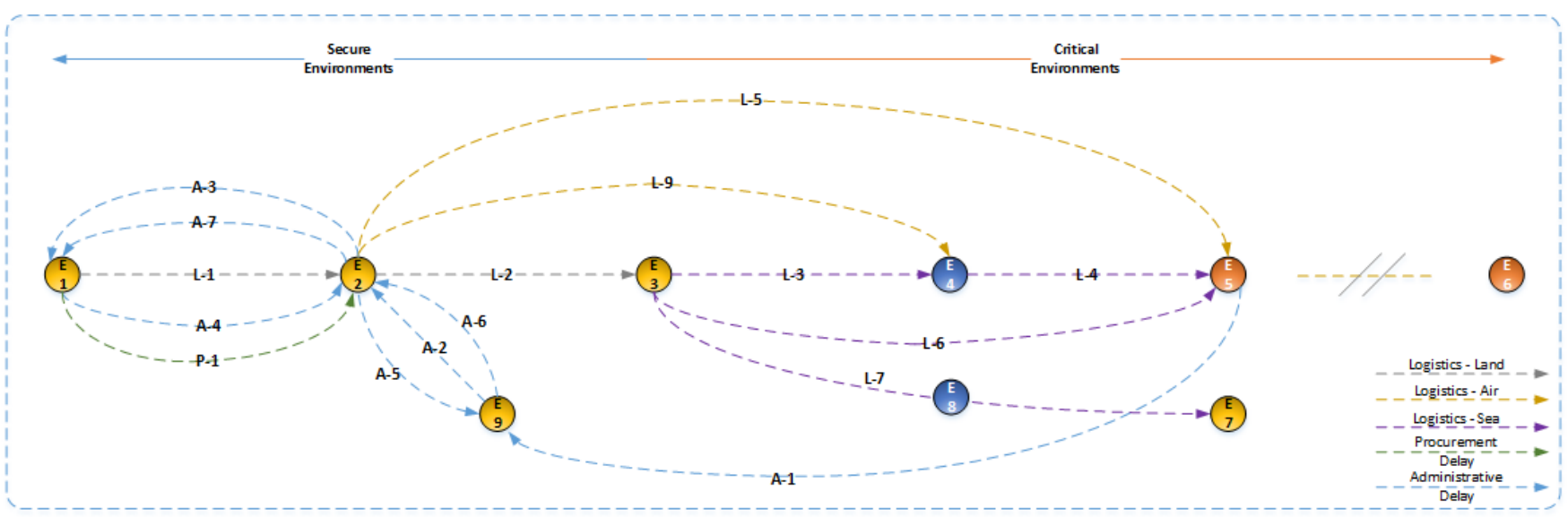

Figure 2 - Classic DS2 System

This section aims to investigate current practices in DS2 and outline key information on classic DS2 systems. In order to do this various structured and unstructured interviews have been carried out with senior engineers of a leading British DS2 provider.

The interviews allowed the authors to gather data and information to develop generic visual/conceptual models. After validation of the models the authors have carried out analysis through deductions and assumptions.

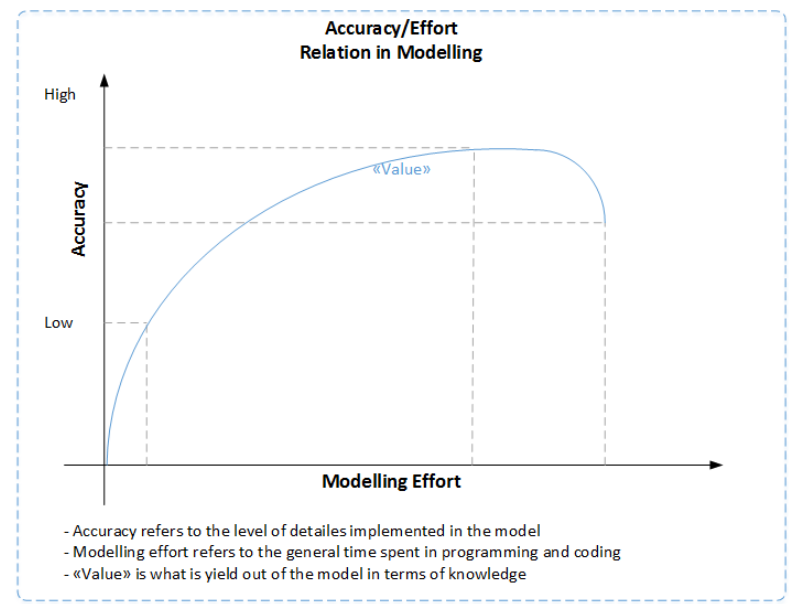

Figure 3 - Accuracy/Effort relation

DS2 systems are in fact very complex, a limited number of options have been included following the principle outlined in Figure 3 - Accuracy/Effort relation developed by Robinson, (2004) which outlines that a highly accurate model might not provide extra value and in fact requires extra effort.
The following sections will cover:

> "DS2 System Analysis": a generic DS2 system is outlined, the system's elements and links are described and finally the "Key Performance Indicator" (KPI) of Availability is described and equation variables are linked to the DS2 system.

> "DS2 System Configuration" (SysCo): outlines all possible scenarios of the supply chain, these represent the option which a DS2 has to deliver value to the Royal Navy.

$>\quad$ "DS2 Operating Environment" (OpEnv): outlines the operating environments in which a DS2 operates. OpEnv have strict requirements which have to be met in order to accomplish their aims.

The collection of System Analysis, SysCo and OpEnv provide a simplified but exhaustive representation of a classic DS2 system, its relations and dynamics. Moreover this collection represents the minimum complexity which has to be modelled.

\subsection{Classic DS2 - "System Analysis" (SA)}

A DS2 provider aims to support complex engineering systems installed on defensive platforms. In the case of the Royal Navy, these platforms are aircraft carriers, destroyers, frigates and submarines. The Royal Navy platforms are featured with the ability to operate everywhere in the world in complex and critical environments. This implies that a Royal Navy's DS2 provider has to cope with extended supply chains. In 
some cases these supply chains may be disrupted such as situation of battle theatre where the presence of threats may limit operations. Figure 2 represents a DS2 as a system and outlines the end-to-end process of a DS2 to provide value to the Royal Navy. A DS2 system delivers its value through the interaction of various system elements $\left(E^{\circ}\right)$ which are connected through links $\left(L^{\circ}, A^{\circ}\right.$ and $\left.\mathrm{P}^{\circ}\right)$. The Royal Navy is involved partially with the DS2's operations and perceives value through a "Key Performance Indicator" (KPI) of the complex systems to be supported, Availability. Availability is a measure of uptime over total-time (uptime + downtime) and measures the predicted ability of a complex system to achieve its purpose when required to do so.

$$
A_{o}=\frac{\text { Uptime }}{\text { Uptime }+ \text { Downtime }}
$$

\subsection{System Elements}

A DS2 is made of 9 system elements which can be divided into static elements, active non-critical elements and active critical elements.

\begin{tabular}{|l|l|c|l|}
\hline Tag & \multicolumn{1}{|c|}{ Description } & \multicolumn{1}{|c|}{ Classification } \\
\hline E1 & Suppliers & $\begin{array}{l}\text { Defence Support } \\
\text { Service Provider }\end{array}$ & Static in safe environment \\
\hline E3 & Royal Navy Port & & Static in safe environment \\
\hline E4 & $\begin{array}{l}\text { Surface Support } \\
\text { vessel }\end{array}$ & $\begin{array}{l}\text { Static, partially in safe } \\
\text { environment }\end{array}$ \\
\hline E5 & $\begin{array}{l}\text { Defence } \\
\text { platform }\end{array}$ & $\begin{array}{l}\text { Active, critical } \\
\text { environment }\end{array}$ \\
\hline E6 & $\begin{array}{l}\text { Defence } \\
\text { platform }\end{array}$ & $\begin{array}{l}\text { Active, critical } \\
\text { environment (operational } \\
\text { theatre) }\end{array}$ \\
\hline E6 & Forward base & $\begin{array}{l}\text { Active, critical } \\
\text { environment (battle } \\
\text { theatre) }\end{array}$ \\
\hline & Mossel & $\begin{array}{l}\text { Active, critical } \\
\text { environment (operational } \\
\text { theatre) }\end{array}$ \\
\hline
\end{tabular}

Table 2 - System's Elements description

As previously described, a DS2 system's elements need to interact with each other in order to deliver value to Royal Navy. This interaction is given by three links: 1) logistics $\left.\left(\mathrm{L}^{\circ}\right), 2\right)$ Administrative delay $\left(A^{\circ}\right)$ and 3$)$
Procurement delay $\left(\mathrm{P}^{\circ}\right)$. These links are therefore critical variables of an expanded equation of Availability. A DS2 provider wants to minimise these values in order to maximise Availability.

$$
A_{o}=\frac{O_{t}+S_{t}}{O_{t}+S_{t}+P M_{t}+C M_{t}+A D_{t}+P D_{t}+L D_{t}}
$$

Equation 2 - Operational Availability

\begin{tabular}{|c|}
\hline Description \\
\hline $\boldsymbol{O}_{\boldsymbol{t}}=$ Operating Time \\
$\boldsymbol{S}_{\boldsymbol{t}}=$ Setup Time \\
\hline $\boldsymbol{P} \boldsymbol{M}_{\boldsymbol{t}}=$ Planned Maintenance Time \\
\hline $\boldsymbol{C} \boldsymbol{M}_{\boldsymbol{t}}=$ Corrective Maintenance Time \\
\hline $\boldsymbol{A} \boldsymbol{D}_{\boldsymbol{t}}=$ Administrative Delay Time \\
\hline $\boldsymbol{P D}_{\boldsymbol{t}}=$ Procurement Delay Time \\
\hline $\boldsymbol{L D}_{\boldsymbol{t}}=$ Logistic Delay Time \\
\hline Table 3 - Equation description
\end{tabular}

Given the use of deployable and active platforms, which may operate remotely in the world, the major factor which negatively influences Availability is given by the logistic delay time (LDT), and its relation with distance and speed of delivery. In order to cope with this problem (distance), platforms are featured with small warehouses to keep inventory of critical-to-availability components. Unfortunately defence platforms have various units of complex systems featured with extended number of subsystems and components. For example, the "Highly Mechanised Weapon Handling System" (HMWHS) is made of 17 sub-systems with a total of 1500 components. A defence platform does not have enough capacity to keep all the required components to support its systems. Space is a critical and limited resource and is strictly linked with the survivability metric of the platform. As outlined before, distance is a critical variable which is not controllable by a DS2 provider. The main mitigation strategy to cope with distance is the allocation of spares in the front-end of a DS2 system (support vessels or forward bases). This strategy is fairly complex, requires a large amount of effort and technology in order to be successful. Moreover the forecast of failures of components is a highly complex process and given the high level of uncertainties may lead to inaccurate estimates. 


\subsection{Logistics Delay Time}

"Logistics Delay Time" (LDT) links are outlined in Figure 2. What a DS2 can control, is the responsiveness (given by type of contract, Administrative delay time, inventory levels and Manufacturing lead time of suppliers) and the speed of delivery (given by the Logistics options and transportation type) of a DS2 system through sea, air and land. Generally, the quicker a delivery is, the more expensive it is.

\begin{tabular}{|c|c|c|c|}
\hline Tag & $\begin{array}{c}\text { Referen } \\
\text { ce }\end{array}$ & Icon & Description \\
\hline $\begin{array}{l}\text { L-1 } \\
\text { or } \\
\text { P1 }\end{array}$ & E1-E2 & & $\begin{array}{l}\text { Land transportation between } \\
\text { suppliers/manufacturers of components and } \\
\text { the DS2 provider. }\end{array}$ \\
\hline L-2 & E2-E3 & & $\begin{array}{l}\text { Land transportation between the DS2 provider } \\
\text { and the port, owned and managed by DS2 } \\
\text { provider and operated by Royal Navy. }\end{array}$ \\
\hline L-3 & E3-E4 & & $\begin{array}{l}\text { Port transportation between the warehouse } \\
\text { and the surface support vessel. }\end{array}$ \\
\hline L-4 & E4-E5 & & $\begin{array}{l}\text { Sea transportation between the surface } \\
\text { support vessel and the defence platform. }\end{array}$ \\
\hline L-5 & E2-E5 & & $\begin{array}{l}\text { Air transportation between the DS2 provider } \\
\text { and the defence platform. }\end{array}$ \\
\hline L-6 & E3-E5 & & $\begin{array}{l}\text { Port transportation between the warehouse } \\
\text { and the defence platform. }\end{array}$ \\
\hline L-7 & E3-E8 & & $\begin{array}{l}\text { Port transportation between the warehouse } \\
\text { and the commercial. }\end{array}$ \\
\hline L-8 & E8-E7 & & $\begin{array}{l}\text { Sea transportation between the Commercial } \\
\text { vessel and the forward base }\end{array}$ \\
\hline L-9 & E2-E4 & & $\begin{array}{l}\text { Air transportation between the DS2 provider } \\
\text { and the surface support vessel. }\end{array}$ \\
\hline
\end{tabular}

Table 4 - Logistics Links

Table 4 - Logistics Links outlines all the possible logistic links and type of transportation of a DS2 provider. These logistic links lead to a wider range of options ( $\left.\mathrm{N}^{\circ} 15\right)$ which is investigated in "DS2 -System Configurations" (SysCo) later on.

\subsection{Administrative Delay Time}

The "Administrative Delay Time" (ADT) is a particular element of traditional spare parts contracts between DS2 providers and "Ministry of Defence" (MoD). ADT is made of 7 links outlined in Figure 2. The ADT sequence is described assuming the rule that spare parts are not available in E2, E3, E4, E5, E6, E7 and E8 (this represents the worst case scenario given the highest distance).

As outlined in Table 5- Administrative Delay links, the sequence of the ADT is time consuming and not value adding. ADT in "Contracting for Availability" (CFA) is theoretically eliminated or dramatically reduced, improving the overall performance of the DS2 system.

\begin{tabular}{|c|c|l|}
\hline Tag & Reference & \multicolumn{1}{c|}{ Description } \\
\hline A-1 & E5-E9 & $\begin{array}{l}\text { Defence platform sends the request for a spare part to } \\
\text { MoD. }\end{array}$ \\
\hline A-2 & E9-E2 & MoD sends a request for quotation to DS2 provider. \\
\hline A-3 & E2-E1 & DS2 provider send request for quotation to supplier. \\
\hline A-4 & E1-E2 & $\begin{array}{l}\text { Supplier sends DS2 provider price and time of deliver } \\
\text { between E1-E2. }\end{array}$ \\
\hline A-5 & E2-E9 & $\begin{array}{l}\text { DS2 provider computes its price for spare part and } \\
\text { delivery time between E2-E5. }\end{array}$ \\
\hline A-6 & E9-E2 & $\begin{array}{l}\text { MoD negotiates with DS2 provider and if successful } \\
\text { places order. }\end{array}$ \\
\hline A-7 & E2-E1 & DS2 provider places order to supplier. \\
\hline
\end{tabular}

\subsection{Classic DS2 - "System Configurations" (SysCo)}

"System Configurations" (SysCo) refers to all the possible options a DS2 provider has, to deliver spare parts to Royal Navy's platforms. SysCos have been sequenced from fastest to slowest, therefore SysCo1 is the fastest and $\mathrm{Sys} \mathrm{Co} 5$ the lowest. It is assumed as a rule that the spare part holder or manufacturer is E1 and there are no available spares in E2, E3, E4, E5, E6, E7, E8 and E9.

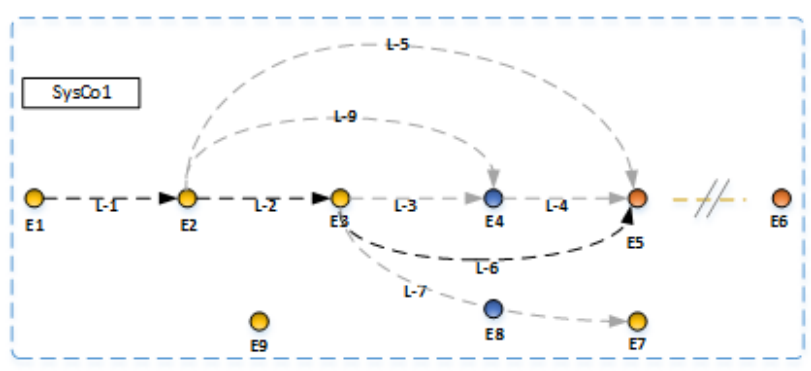

Figure 4 - SysCo1

> SysCo1 outlines a scenario where a defence platform is not deployed and located at the port. SysCo1 is therefore made of L1, L2, L6 (land, land, port) which are fixed and known distances between elements located in safe environments.

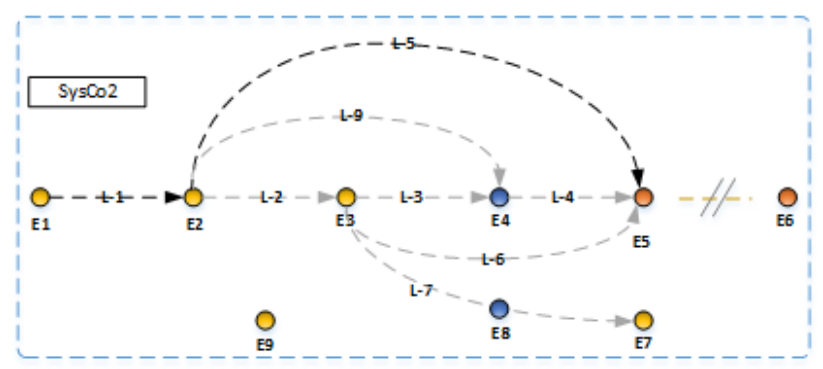

Figure 5 - SysCo2

SysCo2 outlines a scenario where the defence platform is deployed in an operational theatre, therefore it is serviced by a supply chain. SysCo2 is made of L1, L5 (land, air), L1 distance is known while L2 distance is highly variable and scenarios have to be outlined. 


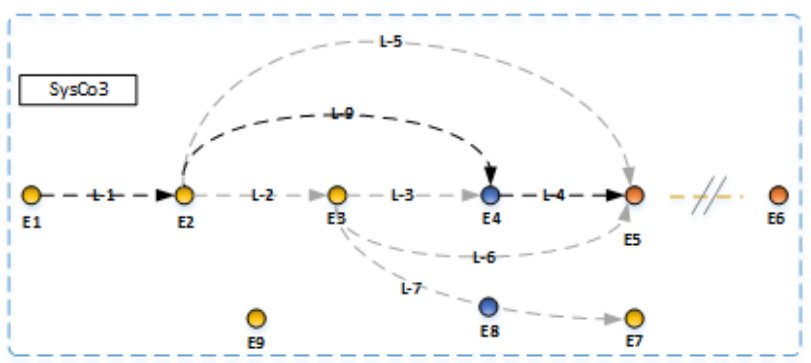

Figure 6 - SysCo3

SysCo3 outlines a secondary air supply scenario where the spare part is delivered through air to a surface support vessel which will approach the defence platform in a secondary phase. SysCo3 is made of L1, L9, L4 (land, air, sea). L9 and L4 distances are highly variable.

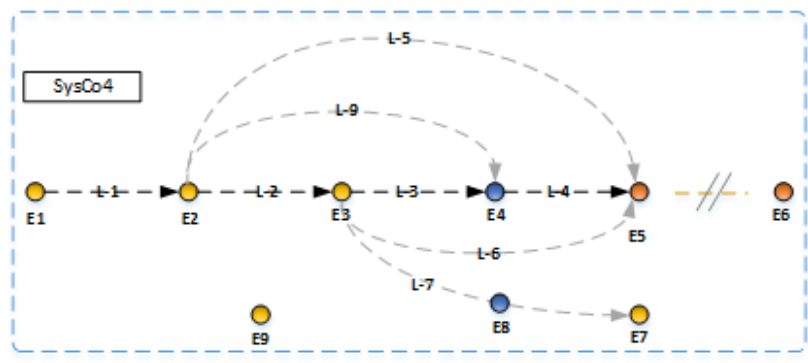

Figure 7 - SysCo4

> SysCo4 outlines a scenario where a surface support vessel is located at the port and will approach the defence platform in a second phase. SysCo4 is made of L1, L2, L3 and L4 (land, land, sea, sea). L1, L2 and L3 distances are known while L4 is again highly variable depending on the location of the platform.

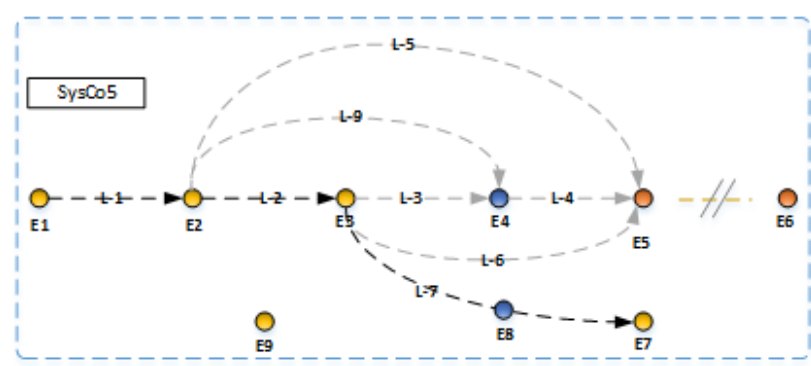

Figure 8 - SysCo5

SysCo5 outlines a scenario where a commercial vessel is located at the port and will approach a forward base in a second phase. SysCo4 is made of L1, L2 and L7 (land, land, sea). L1 and L2 distances are known while $L 7$ varies based on the location of the forward base. Given the use of commercial vessels this is considered a cheap SysCo and the most commonly used.
As follow Table 5 - SysCo rating with a recap of SysCo's and relevant rating on cost, speed and security. The scale is from 1 "worst case" to 5 "best case".

\begin{tabular}{|c|c|c|c|c|}
\hline SysCo & $\begin{array}{c}\text { TAG } \\
\text { Sequen } \\
\text { ce }\end{array}$ & $\begin{array}{l}\text { Logistics } \\
\text { Type }\end{array}$ & Cost & Speed \\
\hline SysCo1 & $\begin{array}{l}\text { L1, L2, } \\
\text { L6 }\end{array}$ & Land, land, port & 1 & 5 \\
\hline SysCo2 & L1, L5 & Land, air & 4 & 4 \\
\hline SysCo3 & $\begin{array}{l}\text { L1, L9, } \\
\text { L4 }\end{array}$ & Land, air, sea & 5 & 3 \\
\hline SysCo4 & $\begin{array}{l}\text { L1, L2, } \\
\text { L3, L4 }\end{array}$ & $\begin{array}{l}\text { Land, land, sea, } \\
\text { sea }\end{array}$ & 3 & 2 \\
\hline SysCo5 & $\begin{array}{c}\text { L1, L2, } \\
\text { L7 }\end{array}$ & Land, land, sea & 2 & 1 \\
\hline
\end{tabular}

Table 5 - SysCo rating

This section investigates the current DS2 practices. The research approach used consisted of carrying out interviews with experts to feed a conceptual modelling phase. The conceptual model developed, outlined in figure 2 has been validated by the experts. Afterwards an analysis of the conceptual model has been carried out. The analysis provided an overview of a DS2 system, outlining what are the system elements, what is the flow of the system, what are the triggering events, what are all the possible options of configuration and finally what is the system's performance ratio, and availability. Availability measures are the ability of a system or equipment to perform its function when required to do so. A DS2 system's performance is given by the availability of the system or equipment it supports, the most impacting factors are given by ADT, PDT and LDT. It can be concluded that the owner of the system or equipment to be supported (in defence MoD), wants to maximise availability by reducing ADT, PDT and LDT. Currently the MoD establishes two types of contracts to support its system or equipment, spare parts contract and "Contracting for Availability" (CfA). In the first case the service provider's profits are linked with the number of failing parts. The service provider does not have a financial interest in improving availability and the performance of the DS2 system. In the case of CfA, the service provider agrees with MoD a certain level of availability to be guaranteed over an extended number of years for a certain price. In this case the DS2 provider has strong interest in improving the performance of the DS2 system in order to reduce its costs and maximise its profitability. With CfA contracts, both the service provider and the MoD have a mutual advantage. 


\subsection{Classic DS2 - "Operating Environments" (OpEnvs)}

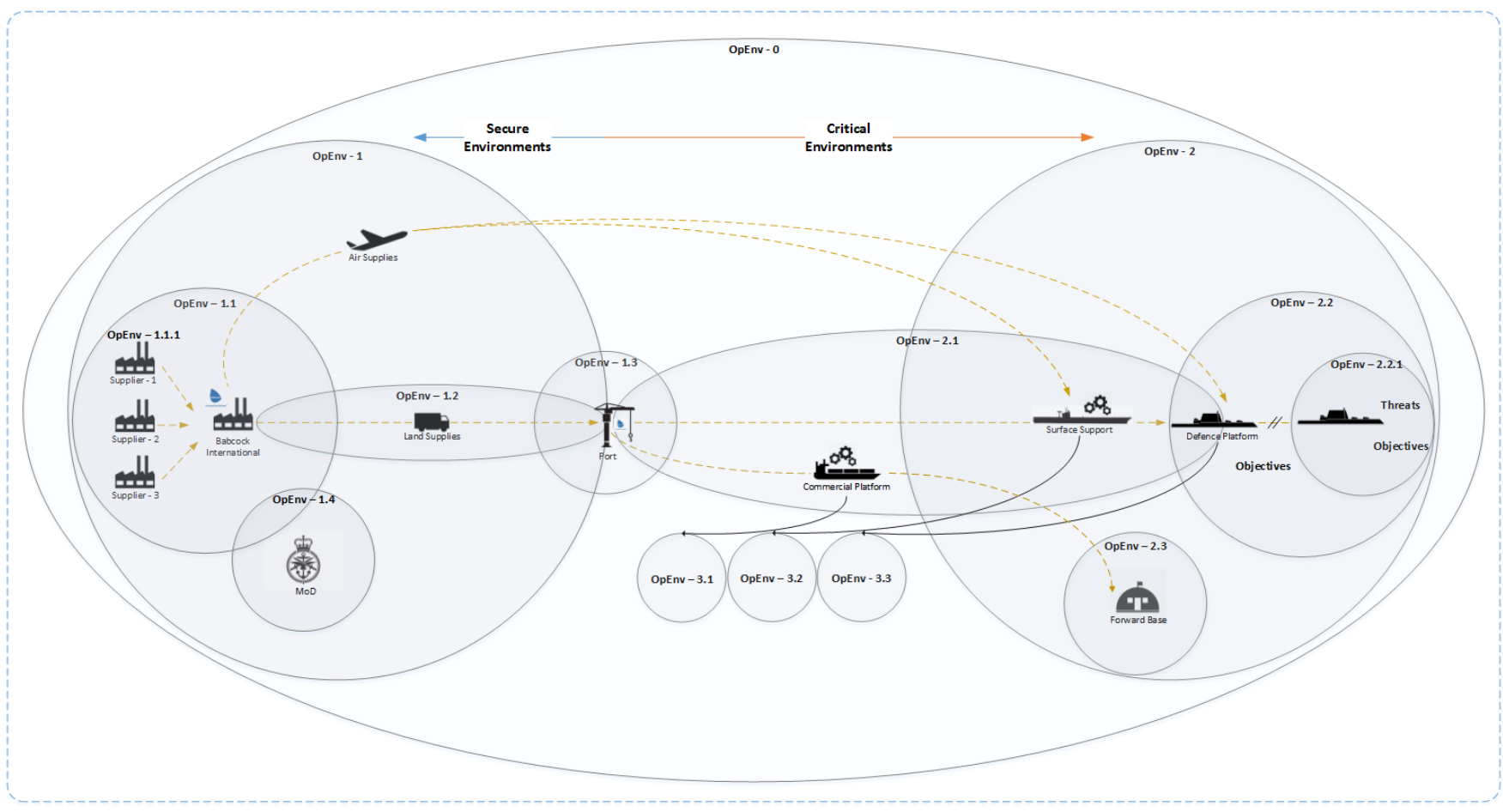

Figure 9 - "Operating Environments" (OpEnvs)

This section investigates the "Operating Environment" (OpEnv) in which a DS2 system operates. As outlined previously DS2 systems operate in safety and mission critical environments featured with extended and disrupted supply chains.

Figure 9 outlines OpEnv0 which is the macroenvironment of a DS2. OpEnv0 is featured by "criticality" which is given by both, 1) the state of an OpEnv0 and the progression to the front-end of the DS2 system as outlined in Figure 9. OpEnv0 is made of two main subenvironments, 1) OpEnv1 which represents the land where the facilities of a DS2 provider are located, the suppliers, the land supply chain and the MoD. OpEnv2 represents the war theatre, which is usually located remotely from OpEnv1 and featured with high criticality. OpEnv2 is further broken down into OpEnv2.2, the operational theatre" and OpEnv2.2.1 the battle theatre. While OpEnv2.2 is served by a supply chain (air and sea), OpEnv2.2.1 is featured by a disrupted supply chain implying total isolation of the entities operating in it.

Table 6 - OpEnv1, 2, 3 outlines and describes each of the remaining operating environments in which a DS2 operates.
Outlines the OpEnv of the home land and groups together DS2 system stakeholders

OpEnv1.1

Outlines the OpEnv in which the DS2 provider and its suppliers operate OpEnv1.2

Outlines the OpEnv of the land supply chains

OpEnv1.3

Outlines the OpEnv of the port where a DS2 operates with the MoD OpEnv1.4

Outlines the OpEnv in which MoD operates

\section{Table 6 - OpEnv1}

\section{OpEnv2}

Outlines the OpEnv of a war theatre and is featured with active deployable platforms

OpEnv2.1

Outlines the OpEnv in which support vessels operate

OpEnv2.2

Outlines the operation theatre of a defence platform which is served by the supply chain

OpEnv2.2.1

Outlines the battle theatre of a defence platform in which the supply

chain is disrupted

OpEnv2.3

Outlines OpEnv of a forward base

Table 7 - OpEnv2

Outlines the OpEnv inside the pla

OpEnv3.1

Outlines the OpEnv of a submerged support vessel

OpEnv3.2

Outlines the OpEnv of a surface support vessel

OpEnv3.3

Outlines the OpEnv of a defence platform 


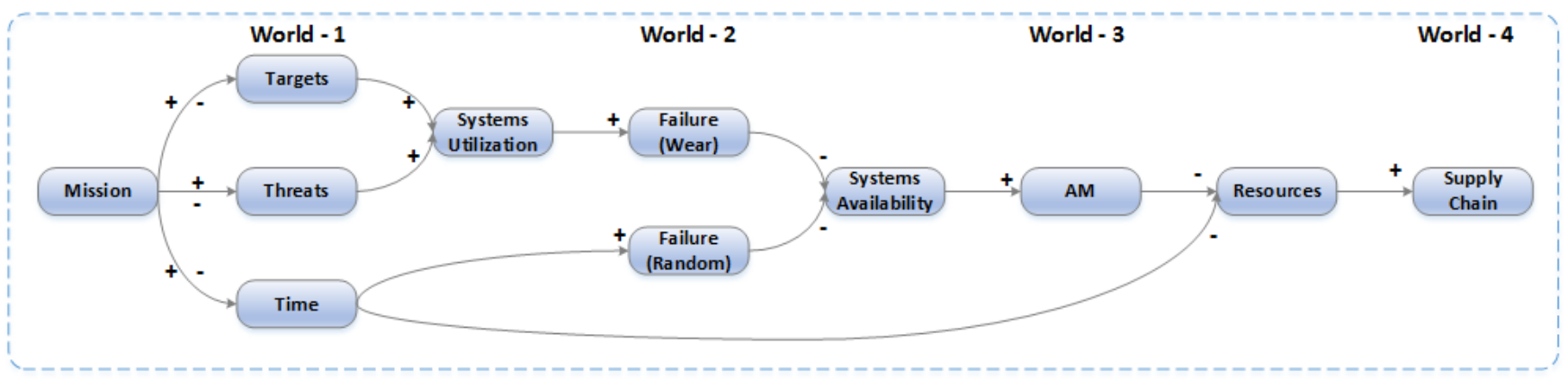

Figure 10 - System Dynamics visualisation

OpEnv0 can be featured by three states, 1) war state which implies high risk levels due to military threats, 2) crisis state featured with medium risk levels due to insurgence or natural disaster and finally 3) peace state featured with low levels of risk due to weather conditions and random events.

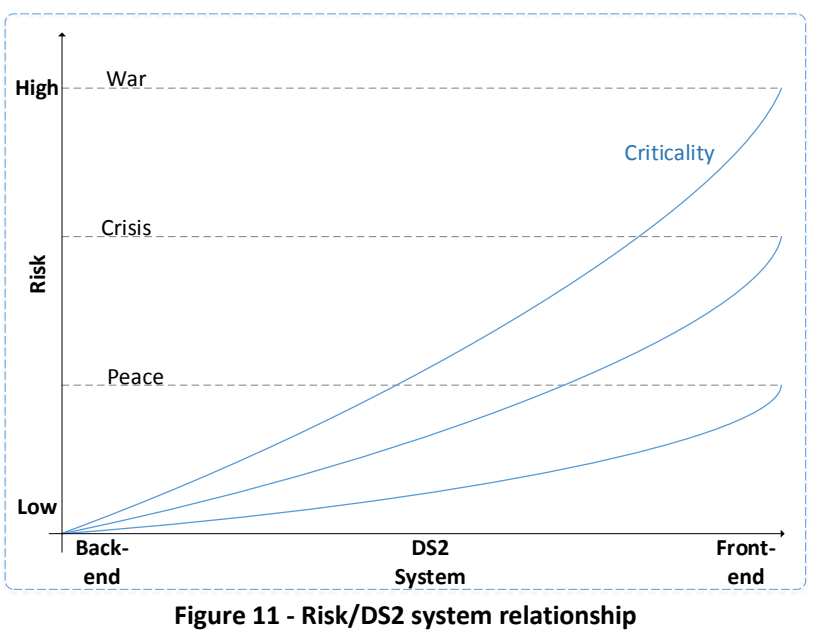

Criticality is a key element which has dramatic impact on the DS2 system's performance and cost. Moreover there is a relationship outlined in Figure 11 - Risk/DS2 system relationship which implies an increase of environment requirements with an increase of criticality. If a DS2 system's element does not meet the minimum level of requirements to cope with the related level of criticality, the element is subject to vulnerability (i.e. is not able to cope with risks which may occur within that OpEnv).

Finally it has to be outlined that OpEnvs can be discerned into internal and external OpEnvs. Internal OpEnvs are the one of the support platforms and defence platforms (OpEnvs3.1, 3.2, 3.3).

\section{DS2 System Dynamics}

Figure 10 outlines the factors which defines the dynamics of a DS2. A DS2 is triggered by failures of components. Failure are due to random events or due to systems utilization. The utilization of a system are triggered by the occurrence of threats and by the targets of the mission of the platform. The dynamics of a DS2 can be grouped in four different classes or worlds which collectively provide an exhaustive representation on how a DS2 is triggered and evolves over time:

- World1: represents the external world in which a platform operates. This is given by a mix of controllable and uncontrollable events such as targets, threats and time as duration of a mission. Targets and threats represent the triggering events which influence the whole DS2 system.

Dorld2: represents the systems which allow the platform to be successful and survive. World1 influences the utilization of these systems, the higher utilization the higher failure rate due to wear. Moreover failure might be random and the probability of occurrence of random failure is related to the progression of time.

> World3: represents the RAS2 (only in next generation DS2), its manufacturing system and its stocks of raw materials. A drop in Availability triggers the RAS2 which consequently consumes its resources which are limited. In case of current practices this world represents the warehouse where components are held.

Dorld4: represents the supply chain and the logistics of the DS2. The reduction of resources due to the operation of the RAS2 triggers the supply chain to restore its resources.

It can be concluded that the driving factor of a DS2 is the mission of the platform, which will define what will be the behaviour of the platform and consequently the behaviour of the DS2 in order to support the platform during its mission. 


\section{Defining the behaviour of the Platform}

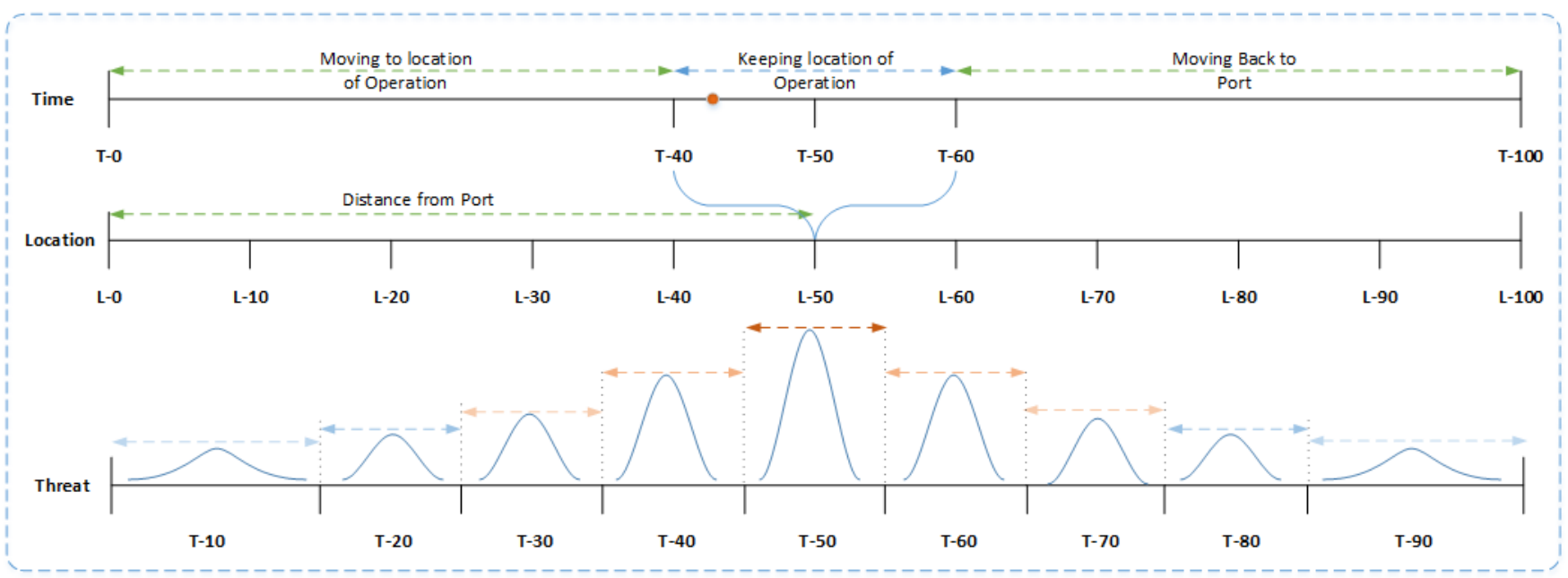

Figure 12 - Factors

This section investigates the factors which influences and rules a platform's behaviour. Previously it has been outlined that a DS2 system is triggered by failures of system's components. When a system's components fails and the related spare part is not held in the platform, the DS2 system is triggered and its SysCo will vary and adapts based on 1) location of the platform and 2) criticality of the component (speed of delivery).

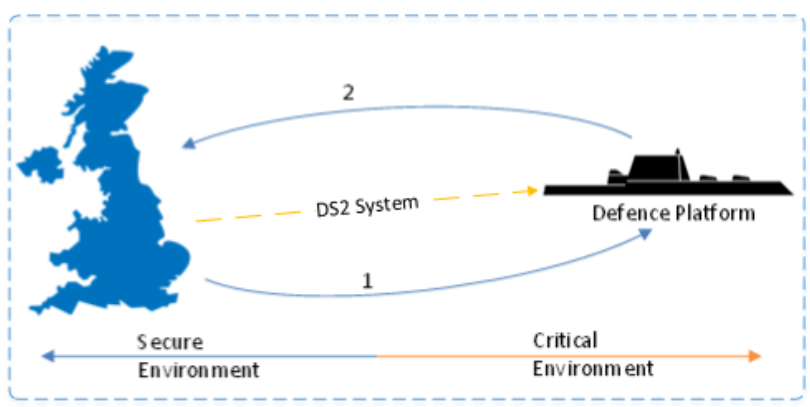

Figure 13 - Mission Loop

The mission of a platform is considered as a loop as outlined in Figure 13 and the DS2 system evolves based on the location of the platform. Failures might be random but are mainly due to the system's utilization which is influenced by platform's behaviour. The platform's behaviour is ruled by four main factors 1) mission aim, 2) mission time, 3) the related location to certain times and 4) related threats associated to that location. The first three factors are internal and known while the fourth factor, "threats" is unknown and given by the reaction of the counterpart in order to limit or disturb the platform during its mission or to prevent the platform from accomplishing its mission. What is known is that, if the platform's location of operation is in OpEnv2 "War theatre", the probability of occurrence of threats is higher than OpEnv1 "Secure Environment". This is mainly given by the control of the counterpart over the territory. Figure 12, groups together the three factors represented as axis and outlines other critical information which is critical in defining a DS2 behaviour and configuration. The first axis outlines the progression of time with T-0 the beginning of the mission and T-100 the end of the mission. The mission defines a route which the platform has to follow in order to arrive to a "location of operation". The first phase is a transition to the location of operation, the second phase is about holding the location and operate over a period of time (i.e. from T-40 to T-60) and finally the third phase is the transition of the platform back to the port or to another friendly port. Figure 12 outlines that to each point of the first axis relates a point on the second axis "Location". The Location axis defines in which OpEnv the platform is situated with a related distance from OpEnv1 "Secure Environment" where the DS2 facilities are located. The distance between OpEnv1 and the location of the platform is a critical measure as it defines the way a DS2 system can deliver the component with its SysCos. Moreover the criticality of the component plays a crucial role in defining the speed of delivery. If a component is considered highly critical for mission and safety this will be delivered through SysCo2 or "air deployment" (threats not considered). Finally, the third axis outlines the probability of occurrence of threats. The probability grows with the progression to OpEnv2 "War theatre" and achieves its maximum in OpEnv 2.2.3 "Battle theatre". In this situation the supply chain is disrupted given the high level of threats. Threats play also a determinant role in the SysCo selection as the support platform which delivers the spares is subject to threats as well. 


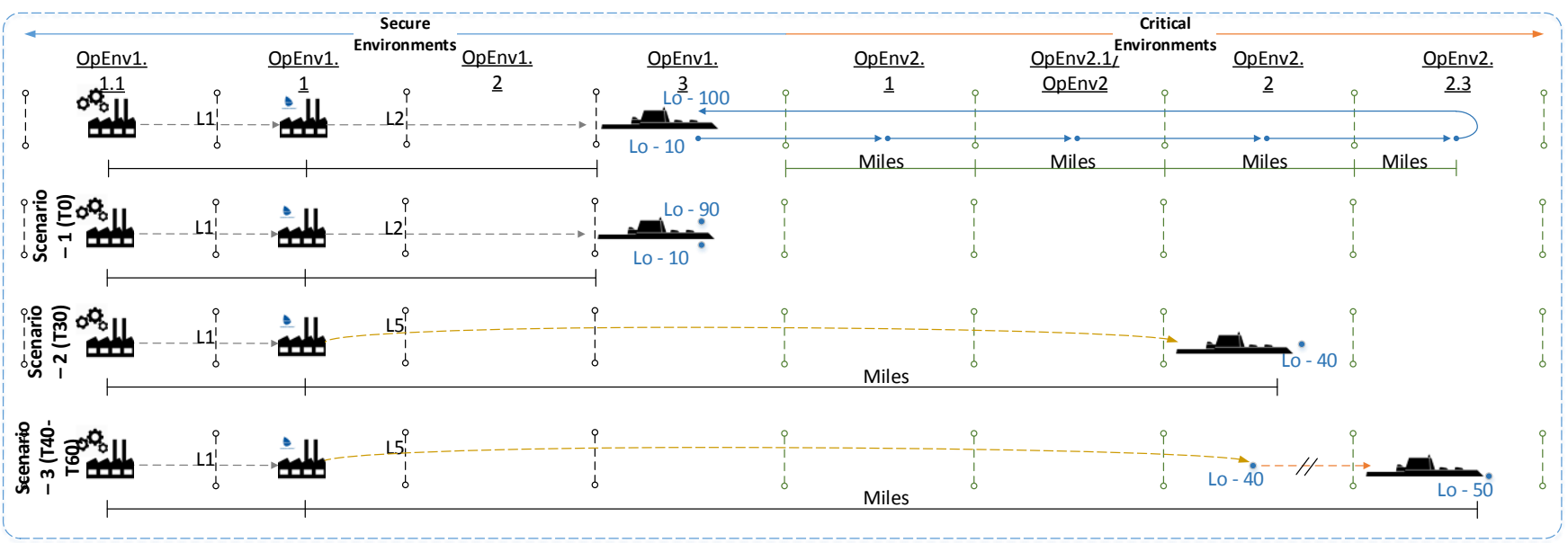

Figure 14 - DS2 evolution over mission time

In order to outline the evolution of a DS2 system in relation to mission time an example has been outlined in Figure 14 which assumes that the platform is located in OpEnv1.3 and has to reach OpEnv2.2.3 and return to OpEnv1.3. Speed, transitions, time of position hold and threats are not considered. Moreover, the platform has no intermediate support (forward base or support vessel), the spares have to be delivered as quickly as possible. Three scenarios have been outlined: scenario-1 time of mission is T0 and related location is Lo-10 in the port, the related SysCo is SySco1 with land delivery. Once the mission starts and progress over time the SysCo will evolve and adapt based on the requirements of the situation. Scenario-2 the time of mission is T30 and related location is Lo-40 in OpEnv2.3 "operation theatre". The related SysCo is SySco2 with air delivery. The platform can be supported as OpEnv2.3 is featured with a stable supply chain. Finally, in scenario-3 the mission has reached T40 and the platform is located within OpEnv.2.2.3 "Battle theatre" which cannot be served by a DS2 system as the supply chain is disrupted. Therefore, the spares can be delivered only in OpEnv2.2.

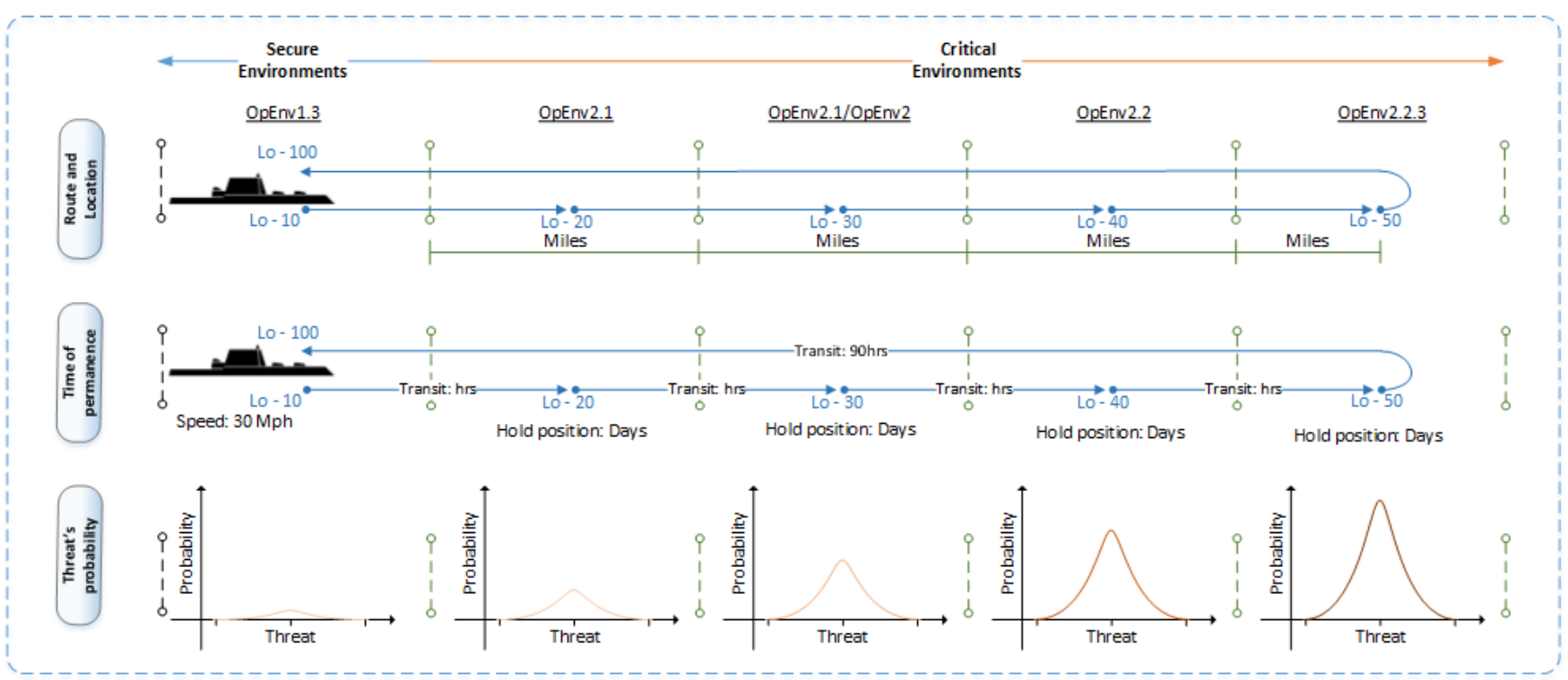

Figure 15 - Speed and times of hold

Finally, Figure 15 outlines more information related to the time of transition between a location and the other and the time that the platform holds the position. As stated previously we assume that the probability of occurrence of threats increases with the progression to OpEnv2.2.3. Moreover, has to be outlined the total time spent in each OpEnv. This is given by the speed of the platform, the route of the mission and the requirements of the mission. The more a platform operates within an OpEnv the more it is likely to be subject to the occurrence of threats. 


\section{The Framework}

The Framework has been developed using as input the current DS2 practices, the system dynamics of a DS2 and previous research published by Busachi et al. (2015a) and Busachi et al. (2015b). Moreover, industrial experts, outlined in Table 1, have been involved during the Framework development. Questions such as "What are the necessary phases to assess AM applications in DS2?", "What is a standard process map of an AM deposition", "Which are the most common SysCos used currently in industry?" and "Which AM technologies should be targeted for DS2 application" have been asked. Results have been recorded and validated after the interviews. The Framework outlined in Figure 20, is made of 8 mutually exclusive phases which collectively allow to carry out and exhaustive assessment of AM application in DS2, test different scenarios of SysCos and compare the current practices with the next generation practices.

\subsection{Transition to AM}

A critical part of the Framework is related with the transition from traditional manufacturing to AM depositions. Once the components are identified, the geometries need to be processed in real life to understand how the AM technology can print this component. Moreover, this phase will outline the product cost and the time of deposition and compare it with the traditional way of producing it.

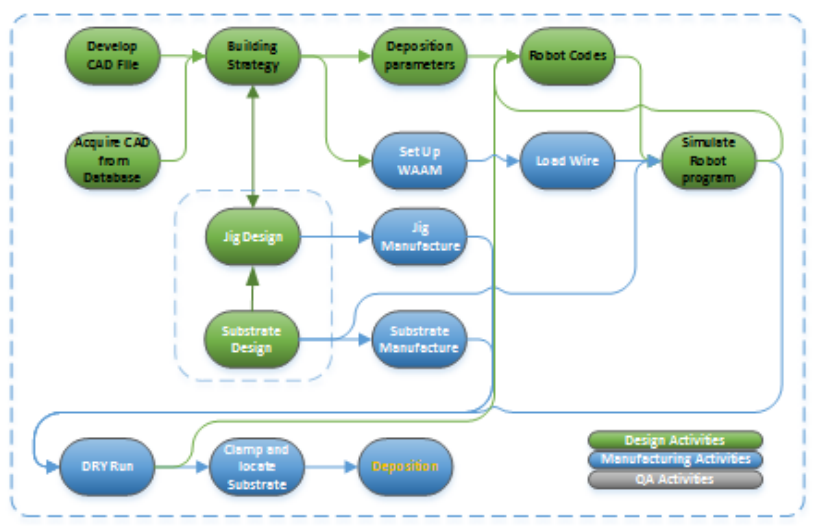

Figure 16 - Design for AM

Figure 16 - Design for AM outlines all the necessary "design activities" required to translate a 3D CAD file into an executable robot program for the actual deposition. Furthermore, as the components have been designed for traditional manufacturing, there might be a possibility to manipulate the geometry of the component for improved efficiency, lightweight or robustness. This is given mainly by the ability of AM for design freedom and complexity (Busachi et al., 2015a). In order to shift from traditional manufacturing to an $\mathrm{AM}$ environment the following has to be carried out in order to define an endto-end AM manufacturing system.

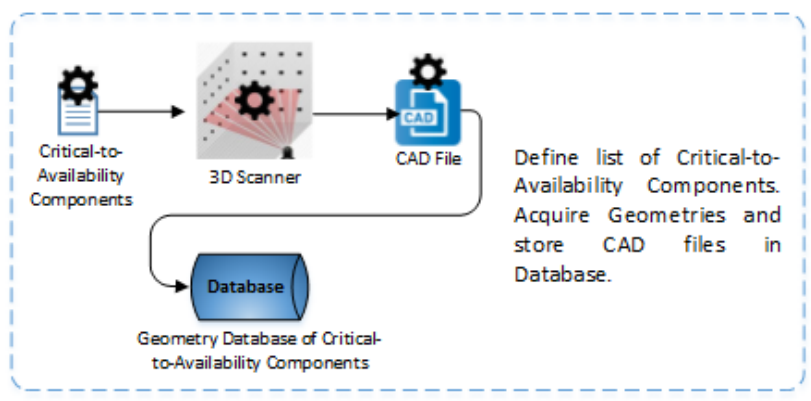

Figure 17 - Geometries database

Once the "Critical-to-Availability" list of components has been identified a database containing all the CAD files has to be developed. If a CAD file is not available, the geometry has to be acquired with a 3D scanner as outlined in Figure 17 - Geometries database.

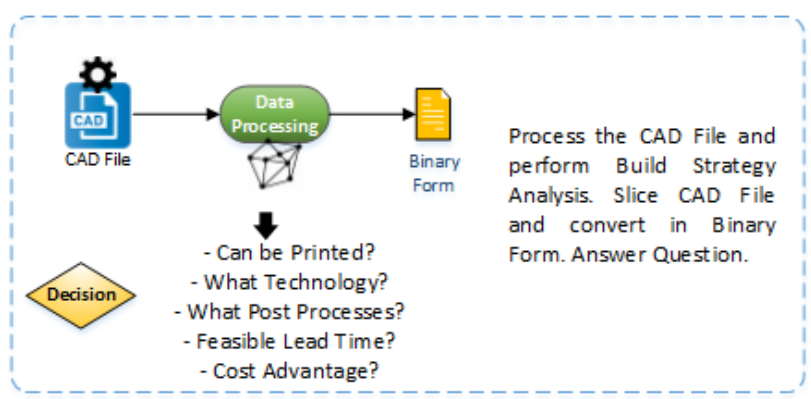

Figure 18 - AM assessment

The following step is to process the CAD file and define the building strategy. This will allow an estimation of time for the deposition and product cost through equations and answering critical questions related with the feasibility.

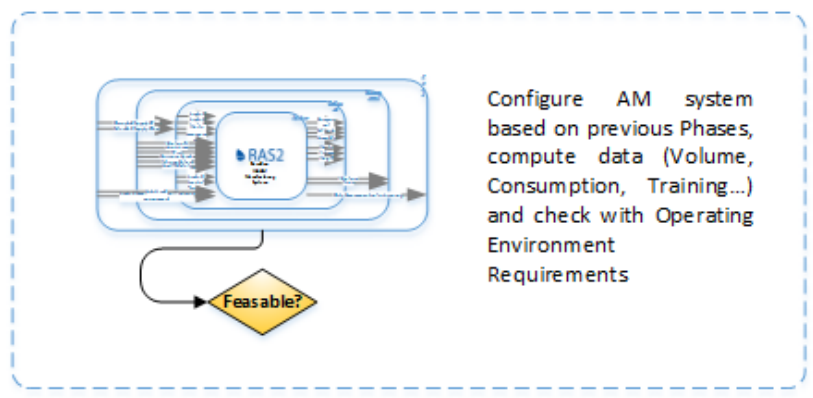

Figure 19 - AM system configuration

Finally, the end-to-end AM manufacturing system has to be defined outlining its post-processes, raw material requirements, its space requirement and utility consumptions which have to be assessed against the platform's OpEnv requirements. 


\subsection{The Framework's Phases}

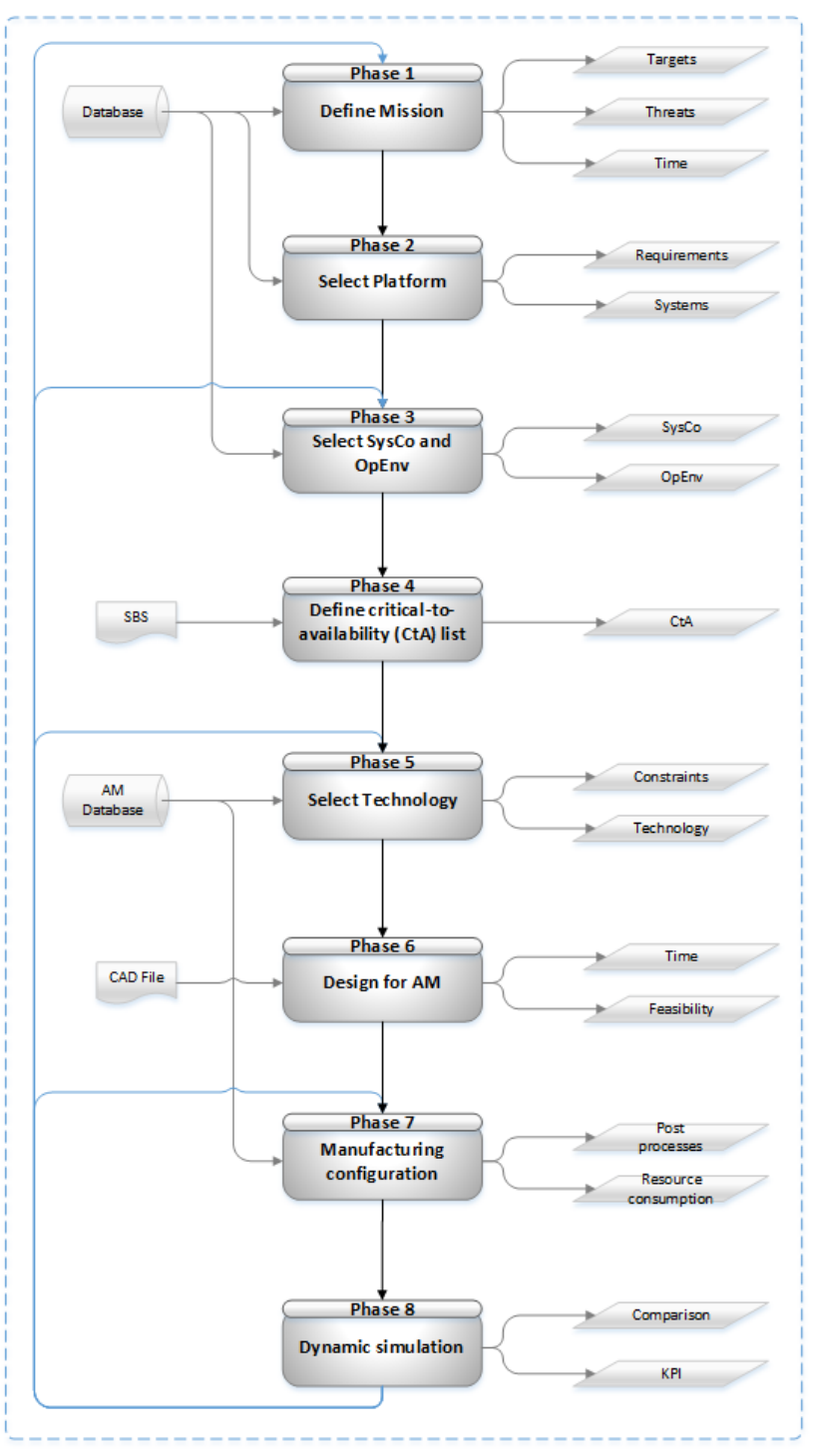

Figure 20 - Framework

$>$ Phase 1 - "Define Mission": outlines the foundation of the assessment of AM applications in DS2. This phase answers key questions such as what type of mission will the platform perform? What is its target? What is the duration? For how long will the platform operate in OpEnv 2.2.1 "battle theatre"? What threats will it encounter?

> Phase 2 - "Select Platform": Royal Navy platforms have various platforms which differ dramatically in terms of their requirements and types of systems installed. It defines rules and limits for the RAS2 and identifies the system.
$>$ Phase 3 - "Select" SySco" and "OpEnv"': as outlined in section 4.2 "Systems Configurations" (SysCo), DS2 have extended possible alternatives, moreover in case of Next Generation DS2 (AM based DS2) these alternatives or options increase due to the delocalisation of manufacturing (RAS2) In-port, In-DS2, In-supplier, In-Support vessel and In-platform. Phase 3 is the one featured with the most interesting "what-if scenarios" and extensive simulation to compare different options of Next generation DS2 will be carried out here.

> Phase 4 - "Define critical-to-availability" list: this phase consists in analysing and classifying functional components of the systems to be supported and outline which one are critical. The input of this phase is represented by a "System breakdown Structure" (SBS) which is a document provided by the "Original Equipment Manufacturer" (OEM) of the system. The document contains a complete list of components with its critical data such as MTBF, MTTR, MLDT, material type, weight and size of component.

$>$ Phase 5 - "Select Technology": this phase is used to select different technologies (SLM, WAAM and FDM) to process the geometry. Technologies have different performance envelope and capabilities.

$>$ Phase 6 - "Design for AM": once the components have been identified and technology has been selected, the geometry has to be processed in order to outline the feasibility, building strategy and KPI such as cycle time and deposition cost.

$>$ Phase 7 - "Manufacturing configuration": this phase outline what processes are required in order to achieve the required quality standard and perform a qualification of the component. This is highly dependent on the material finishing required.

> Phase 8 - "Dynamic simulation": Given 1) high degree of complexity involved, 2) the need to partially represent the dynamics and relations of the real world and 3 ) the requirement to carry out experimentations, the framework has to be translated into a Dynamic Model to carry out simulations and test what-if scenarios. The KPI's which need to be controlled are impact on Availability, cost of delivering the service and logistic delay time. 


\section{Next generation DS2}

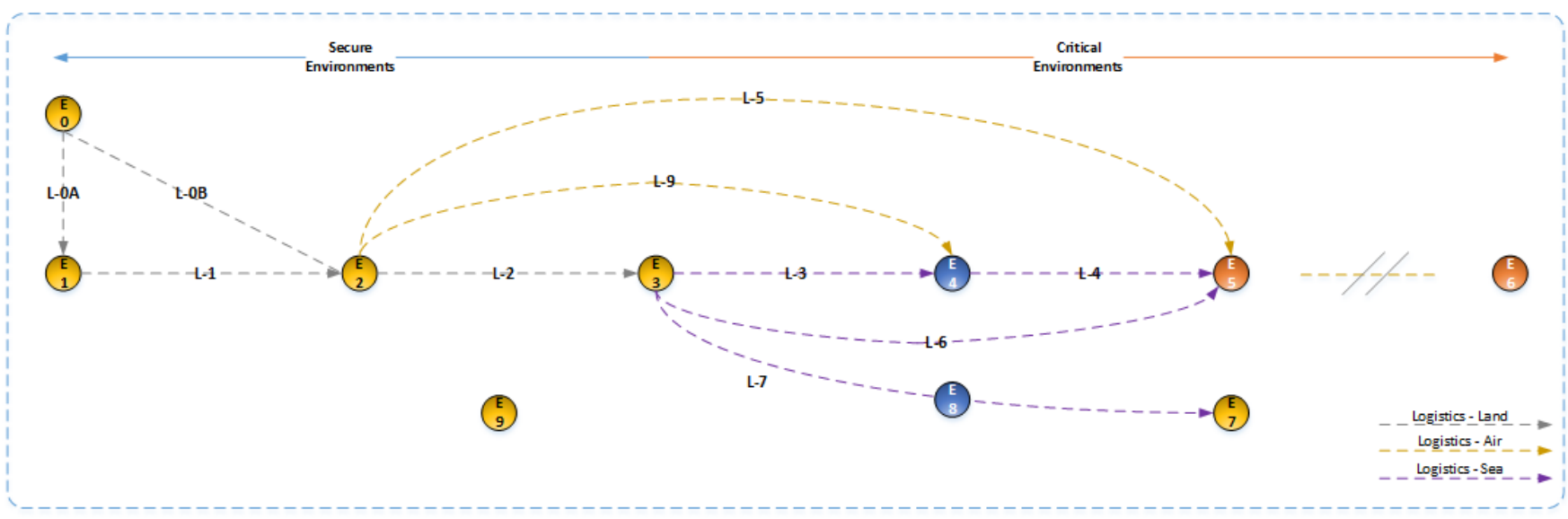

Figure 21 - Next generation DS2

A preliminary comparison between a Classic DS2 and a Next Generation DS2 outlines that the systems remain fairly similar with the only exception that in a NG-DS2 there is a new element, E0, which represents the supplier of raw materials (wire or powder). E0 can supply both, E1 the supplier of components through L-OA and E2 the DS2 provider through L-A1, depending on the location of the RAS2. The system elements represent also the location options for the RAS2 as follows: In-Supplier, In-DS2 provider, In-Port, In-Support vessel, In-Defence platform and In-Forward base.

Furthermore, the "Administrative Delay Time" (ADT) and the "Procurement Delay Time" (PDT) are theoretically eliminated as the utilization of the RAS2 will be limitless and accessible at any given time by MoD operators. Prints will be recorded and charges occurs at fixed times during the year. The RAS2 will enable elimination of OEM's delivery time and also its marginality from product cost. Due to delocalisation, the NG DS2 will be featured with two logistics, an inbound logistic to provide the RAS2 with the raw materials and an outbound logistic to deliver the component to the defence platform. If the RAS2 is located In-Platform, then the outbound logistic is completely eliminated.

$$
A_{o}=\frac{O_{t}+S_{t}}{O_{t}+S_{t}+P M_{t}+C M_{t}+L D_{t}}
$$

Equation 3 - NG DS2 Availability equation

Finally, Equation 3 - NG DS2 Availability equation, outlines the new equation through which Availability of systems supported by NG DS2 can be measured. The LDt will vary based on where the AM equipment is located in the DS2 system. SysCos of NG DS2 are not presented but are in total 21.

\section{Discussion}

The initial results of the research are considered highly promising. By implementing $\mathrm{AM}$ in the Front-end of a DS2, on the platforms, the DS2 performance is dramatically improved. Firstly, non-value adding processes (PDT, ADT) are reduced or eliminated. The MoD personnel will have access to the AM machine any time during the mission and can print components continuously within the platform and waiting time will be due only to the cycle time of the AM machine, post processes, qualification and assembly. By progressing from the Back-end to the Front-end of a DS2 system, the system is featured with critical environments, extended supply chains and in some cases disrupted supply chains. Next Generation DS2, such as the "Rapid Availability Support System" (RAS2) will exploit delocalised manufacturing opportunities. The service provider and the "Ministry of Defence" (MoD) will benefit from:

$>$ Increased support to the availability given a reduced response time.

> Reduced supply chain complexity given only supplies of raw materials such as powder and wire.

$>$ Reduced platform's inventory levels, providing more space.

$>$ Reduced delivery time of the component as the RAS can be located near to the point of use.

The main constraints are related to the qualification of the parts within a platform. 


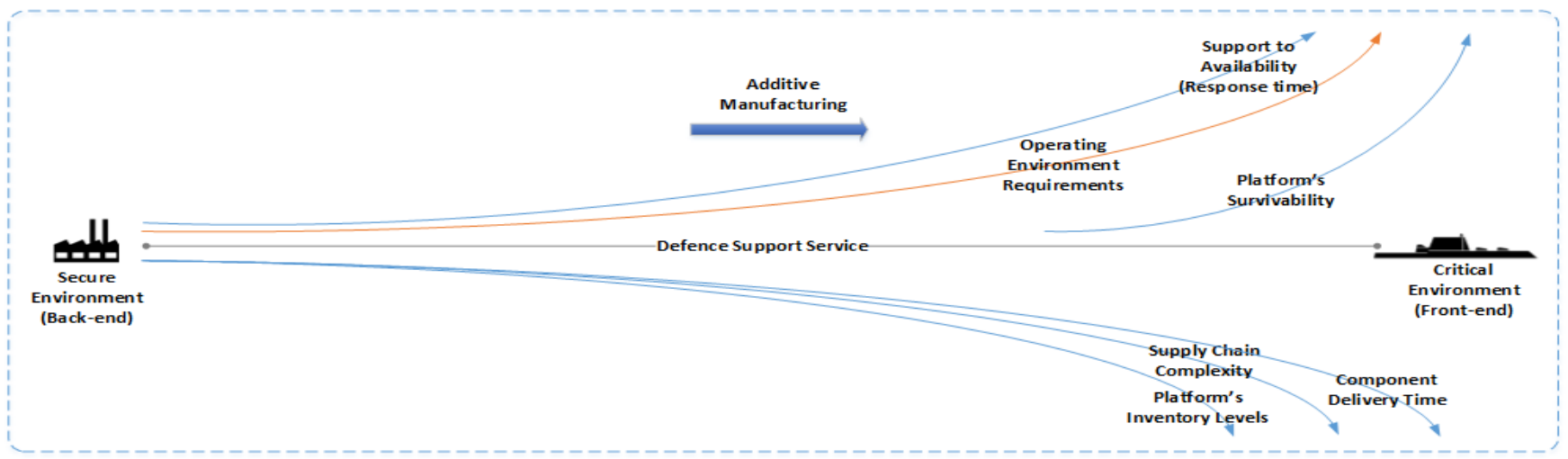

Figure 22 - AM benefits in DS2

AM provides three main advantages which are suitable for the DS2 sector:

$>$ Delocalisation, given the compactness of the technology compared with traditional manufacturing.

$>$ Rapid manufacturing, given its ability to deposit any complex geometry in reasonable times.

$>$ Flexible manufacturing, given its ability to process random geometries without any impact on time and cost.

These three main advantages of AM have a strong fit within the DS2 type of environment given the need for delocalisation within OpEnv with limited space. Moreover, as outlined previously, a platform is featured with an extended number of systems with different components. In fact, the failures may be due to wear or random failures, making it unclear what the demand will look like. This requires a machine which is able to process rapidly different geometries at a random order without affecting the overall setup time.

\section{Conclusion}

This paper contributes to the research efforts on Support Services for the defence sector also called "Defence Support Services" (DS2). The main contribution of the paper is 1) to present the current support service practices for Royal Navy through a system approach, 2) to present a framework for the assessment of AM applications in DS2 and 3) to present initial results on a comparison of current practices of DS2 and future practices which exploit AM opportunities and finally 4) to present the future work required to make an exhaustive analysis of AM applications for DS2. The research approach adopted is adopted from "Soft System
Methodology" (SSM) and primary research results are obtained from interviews with experts of DS2 in both academia and industry. Current practices, the framework and the next generation DS2 have been validated with expert's judgement. The framework proposed represents an exhaustive way for carrying out the assessment and putting in context AM within support services. The framework considers the end-to-end process to exploit AM to support systems' availability. It considers all the different scenarios of the real world, the different AM technologies, post processes and design conversion for AM making it a comprehensive tool for carrying out analytical work and support decision. The main constraint is given by the limited user friendliness which requires some future work to translate this framework into a software. The results of the research outlined promising benefits from AM applications within DS2. Firstly, the overall system is dramatically improved through the elimination of non-value adding activities which occur between the Royal Navy, MoD and DS2 provider (ADT and LDT). As the machine is delocalised within the platform and is available without limits, the users can access it whenever a component is required. The MoD is charged in a second phase, when the platform will return to port from its mission. The second important improvement is the location of manufacturing near the point of use, providing major advantages in terms of reduction of transportation. Considering that in a navy context the major contributor to downtime is the MLDT, this aspect represents the major contributor to improved availability. Given the current shift from spare part contracts to "Contracting for Availability" (CfA), the DS2 provider may benefit from improved profitability through the adoption of next generation DS2 based on AM. The third aspect is related to the transformation of the warehouses from keeping physical components to keeping digital 3D drawings stored as CAD files and STL files and powder and/or wire stocks. 


\section{Future Work}

The framework proposed, developed and validated with academic and industrial experts, represents an exhaustive and robust way to assess AM applications within DS2 systems. The results presented till now are obtained through logical deductions on the visual/conceptual models developed during the research. The next step of this research is to develop a software, more specifically a "Decision Support System" (DSS), which is a standalone executable file, able to perform dynamic simulation on AM applications within DS2. Converting the framework into a software able to make dynamic simulation, will allow real time comparison of the different options available (System Configurations) and to obtain data on time and cost of each option and impact on Availability of the systems under CfA. The modelling technique that will be used is "Discrete Event Simulation" (DES), given its ability to represent states of entities and represents events to trigger the system and "System Dynamics" (SD) to account for the behaviour of different "worlds" which interact with each other. The software will contain a database of the different AM technologies applicable to DS2 which are "Fused Deposition Modelling" (FDM), "Selective Laser Melting" (SLM) and "Wire+Arc Additive manufacturing" (WAAM) (A. Busachi et al., 2015a). The technologies are stored within the software as equations which calculate the cycle time of the deposition and the product cost. The user will input: 1) details of the mission of the platform such as targets, threats and time to be simulated 2) select the type of platform, submerged or surface vessel and the systems under CfA and 3) select the SysCos to be monitored and tested. The aim of the DSS is to provide users the comparison of a classic DS2 where spare parts are shipped from land and next generation DS2 where spare parts are manufactured only when required, within the platform. The outputs which are considered critical for valuation are overall Availability, cost and time of service delivered. The software is developed for DS2 providers to evaluate the acquisition of AM capability and to get reliable and accurate estimates on the impact of next generation DS2 outlining both financial benefits and preliminary engineering information.

\section{Acknowledgment}

The Authors thank Dr. Richard Drake and Dr. Chris Watts of Babcock International for their contribution. This research is performed within the EPSRC Centre for Innovative Manufacturing in Through-Life Engineering Services, grant number EP/1033246/1.

\section{Reference List}

Apte, A., Rendon, R., 2009. A Diagnostic Approach to Weapon SYstem Lifecycle Support: The Phalanx Close-In Weapon System. International Journal of Defense Acquisition Management 2.

ASTM, 2013. Standard Terminology for Additive Manufacturing Technologies (No. F2792-12a). ASTM International.

Busachi, A., Erkoyuncu, J., Colegrove, P., 2015a. "A Review of Cost Modelling of Additive Manufacturing for Defence Support Services." International Journal of Production Research.

Busachi, A., Erkoyuncu, J., Colegrove, P., Martina, F., Ding, J., 2015. Designing a WAAM Based Manufacturing System for Defence Applications. Procedia CIRP 37, 48-53. doi:10.1016/j.procir.2015.08.085

Checkland, P.B., 2001. Soft Systems Methodology. Rational Analysis for a Problematic World Revisited, Wiley.

Erkoyuncu et al., 2015. Opportunities for additive manufacturing to address component obsolescence challenges. RAND Corporation.

Ivanova, O., Williams, C., Campbell, T., 2013. Additive manufacturing (AM) and nanotechnology: promises and challenges. Rapid Prototyping Journal 19, 353-364. doi:10.1108/RPJ-12-20110127

Iwata, C., Mavris, D., 2013. Object-Oriented Discrete Event Simulation Modeling Environment for Aerospace Vehicle Maintenance and Logistics Process. Procedia Computer Science 16, 187196. doi:10.1016/j.procs.2013.01.020

Khajavi, S.H., Partanen, J., Holmström, J., 2014. Additive manufacturing in the spare parts supply chain. Computers in Industry 65, 50-63. doi:10.1016/j.compind.2013.07.008

MBDA, 2015. Missile systems, defence systems - MBDA missiles [WWW Document]. URL http://www.mbda-systems.com/ (accessed 12.6.15).

Pérès, F., Noyes, D., 2006. Envisioning e-logistics developments: Making spare parts in situ and on demand. Computers in Industry 57, 490-503. doi:10.1016/j.compind.2006.02.010

RAND, 2013. Future Technology Landscapes. RAND Europe, Cambridge.

REF, 2015. REF Rapid Equipping Force - United States Army [WWW Document]. URL http://www.ref.army.mil/ (accessed 12.6.15). 
Robinson, S., 2004. Simulation: the practice of model development and use. John Wiley \& Sons, Ltd, Chichester, West Sussex, England; Hoboken, NJ.

US Army, 2015. The Official Home Page of the United States Army | The United States Army [WWW Document]. URL http://www.army.mil/ (accessed 12.6.15). 


\section{Additive manufacturing applications in Defence Support Services: current practices and framework for implementation}

\section{Busachi, Alessandro}

Springer Verlag (Germany)

Busachi A, Erkoyuncu J, Colegrove P, Drake R, Watts C, Wilding S, Additive manufacturing applications in Defence Support Services: current practices and framework for implementation, International Journal of Systems Assurance Engineering and Management, Vol. 9, Issue 3, June 2018, pp. 657-674

http://dx.doi.org/10.1007/s13198-017-0585-9

Downloaded from Cranfield Library Services E-Repository 